burial which was formerly practiced among the Indians of North Carolina. He states that in numerous instances burial-places have been discovered where the bodies had been laid with the face up and covered with a coating of plastic clay about an inch thick. A pile of wood was then placed on top and fired, consuming the body and baking the clay, which retained the impression of the body. This was then lightly covered with earth.

INTERESTING additions to our knowledge of the fauna of the Mammoth Cave have recently been made by Mr. F. W. Putuam, of Salem, U.S., who, as a special assistant on the Kentucky State Geological Survey, of which Prof. N. S. Shaler is the director, had great facilities extended by the proprietors of the cave, and he made a most thorough examination of its fauna, especially in relation to the aquatic animals. Mr. Putnam passed ten days in the cave, and by various contrivances succeeded in obtaining large collections. He was particularly fortunate in catching five specimens of a fish of which only one small individual had heretofore been known, and that was obtained several years ago from a well in Lebanon,. Tennessee. This fish, which Mr. Putnam had previously described from the Lebanon specimen under the name of Chologaster, agassizii, is very different in its habits from the blind fishes of the cave and other subterranean streams, and is of a dark colour. It lives principally on the bottom, and is exceedingly quick in its motions. It belongs to the same family as the two species of blind fishes found in the cave. He also obtained five specimens of four species of fishes that were in every respect identical with those of the Green River, showing that the river fish do at times enter the dark waters of the cave, and when once there apparently thrive as well as the regular inhabitants. A large number of the white blind fishes were also procured from the Mammoth Cave and from other sulterranean streams. In one stream the blind fishes were found in such a position as to show that they could go into daylight if they chose, while the fact of finding the Chologaster in the waters of the Mammoth Cave, where all is utter darkness, shows that animals with eyes flourish there, and is another proof that colour is not dependent on light. Mr. Putnam found the same array of facts in regard to the crayfish of the cave, one species being white and blind, while another species had large black eyes, and was of various shades of a brown colour. A number of living specimens of all the above-mentioned inhabitants of the waters of the cave were successfully brought to Massachusetts after having been kept in daylight for several weeks, proving that all the blind cave animals do not die on being exposed to light, as has been stated.

WE have received the Annuaive of the Belgian Academy for 1875. It contains the usual useful information concerning the organisation and work of the Society, the prizes it awards, list of members, \&c. The principal memoir is that of Quetelet, mentioned in NATURE, vol. xi. p. 217 , with a portrait; there are also memoirs, with portraits, of two other deceased members, Charles Poelman, the comparative anatomist, and H. L. F. Partoes, the architect.

THE additions to the Zoological Society's Gardens during the past week include an Australian Cassowary (Casuarius australis), new to the collection, from Australia, presented by the Marquis of Normanby ; a Banded Cotinga (Cotinga cincta) and a Nakedthroated Bell-Bird (Chasmorhynchus nudicollis), from Bahia, purchased; a King Vulture (Gyparchus papa) from Buenos Ayres, presented by Mr. M. Billinghurst; a Bonnet Monkey (Macacus radiatus) and a Macaque Monkey (M. cynomolgus), presented by Mr. H. Lumsden, a Rhesus Monkey (M. erythreus), presented by Mr. W. de Winton, and a Bonnet Monkey, presented by Miss M. Hailes, all from India ; a Black-tailed Antelope (Nanotragus nigricoudatus) from West Africa, purchased.

\section{ON THE MUSCULAR MECHANICAL WORK DONE BEFORE EXHAUSTION}

MUSCULAR exertion may be either dynamical or statical. Dynamical work is generally intermittent, while statical work is generally continuous in its action. The dynamical work done by any muscle before exhaustion is easily measured in kilogrammetres. Assuming the force exerted by any muscle to be $z v$, and if $n$ be the number of times the force is exerted through the distance $h$, until exhaustion sets in, then the total work, $W$, done before exhaustion, is

$$
W=\text { w } h n
$$

If, however, a weight, $w$, be supported on the horizontally outstretched arm, then by the above formula the amount of work is zero, although the arm soon tires out. In his " Principles of Animal Mechanics" pp, 24-44, London, 1873, Mr. Haughton has attempted to estimate the statical work thus done by the muscles of the arm. Let $w=$ the weight, $a=$ weight of arm, $\alpha=$ distance from centre of glenoid cavity to centre of weight, and $t \pm$ time in seconds before exhaustion. The muscles exert a force capable of sustaining the weight of the loaded arm at its centre of gravity. Let $\theta$ be a small arc, through which the arm moves uniformly with an unknown angular velocity $w$ in the time $t$. Then, if $x$ is the distance from the centre of the glenoid cavity to the centre of gravity of the loaded arm, we have--

But since

$$
\text { Total work }=(w+a) \times 0
$$

and

$$
\begin{array}{rlrl}
(w+a) x & =a\left(w+\frac{a}{2}\right), & \\
\theta & =w t, \\
\text { Total work } & =w a\left(w+\frac{a}{2}\right) t \quad \text { we shall have- }
\end{array}
$$

The values of $(a)$ and $(a)$ are easily obtained by direct mea. surement and weight. This formula (2) is, however, no better than $(1)$, for when $\theta$ is zero, $w$ is also zero, and the work would be nothing. Mr. Haughton has, however, used this formula, assuming $\omega=\mathrm{I}$, which value he has deduced from experiments made by myself (Prin. of Animal Mech., pp. 475-7), and published in the School Laboratory, I87r, vol. i. p. 108.*' The experiments were conducted as follows :-

$A$ weight $w=7^{\circ} 00$ kilos, was lifted from a vertical to a horizontal with the shoulder, in a varying time $t$. At the instant the weight reached the horizontal, the muscles were relaxed, and the weight allowed to drop, being caught on a cushion attached to the leg. The intervals of work and rest, $t$, were in all cases equal. ( $I$ intend to repeat these experiments, making the interval of rest constant). Mr. Haughton has repeated my experiments, and has deduced the formula-

$$
s=\frac{A t}{1+\left(\frac{2 \omega}{\pi}\right)^{2} t^{2}}
$$

\begin{tabular}{|c|c|c|c|c|}
\hline$t$ & $u$ (obs.) & $n$ (calc.) & $d$ per cent. & $e$ per cent \\
\hline $1 \cdot 164$ & $15 \cdot 8$ & $22 \cdot 2$ & $-4 r$ & x'9 \\
\hline I.50 & $22 \cdot 8$ & $22 \cdot 8$ & 0 & $2 \cdot 1$ \\
\hline $2 . \infty$ & 18.5 & 217 & -17 & 10 \\
\hline 3.00 & $17 \cdot 3$ & 18.2 & -5 & $1 \cdot 7$ \\
\hline 4.00 & $15 \% 3$ & 15.5 & $-\mathrm{I}$ & 19 \\
\hline 4.50 & $15^{\circ} \mathrm{O}$ & 13.8 & +8 & $\mathrm{I} \cdot 3$ \\
\hline 500 & 143 & $12 \cdot 6$ & +12 & 2.8 \\
\hline 6.00 & 12.8 & 9.4 & +27 & $3 \cdot 1$ \\
\hline
\end{tabular}

where $n$ is the number of lifts before exhaustion. The observa. tions for my right arm are given below.

TABLE I.

The values of the constants in (3) as obtained by Mr. Haughton are, $A=30.4$ and $\frac{2 \omega}{\pi}=0.666$. Substituting these values, and the proper values of $t$ in (3), and we have $n$ (calc). Column $d$ is the difference in per cent. of $n$ (obs.) Each value of $n$ obs. is a mean of four determinations. The probable error of this mean in per cent. of $n$ (obs.) is given in column $e$. The experi-

* These experiments were merely published as a preliminary, in orde that I might pursue the investigation at my leisuge. 
ments of Prof. Haughton are more nearly represented by (3), but that they are in themselves more accurate, is, as will be seen, a matter of douht. One of the deductions which Prof. Haughton makes from (3) is the determination of his so-called "angular velocity," $w=0.666 \frac{\pi}{2}=x \cdot 0472 .{ }^{*}$ The mean value of $z$ as determined from scveral observations is 100 . Hence (2) becomes-

$$
\text { Total work }=\alpha\left(z v+\frac{a}{2}\right) t \text {. }
$$

Besides the difficulties already noticed, the conclusion arrived at in (4) is open to several fatal objections, a few of which I will detail.

$x$. In his reduction resulting in (3), Prof. Haughton assumes the truth of the following law (Prin. An. Mech., p. 442) :"When the same muscle (or group of muscles) is kept in constant action until fatigue sets in, the total work done, multiplied by the rate of work, is constant." By "rate of work" is meant the work per second. But in these experiments the muscles were not "kept in constant action," and even during the interval of work the action of the muscle constantly varies. The "rate of work" is therefore also entirely indefinite.

2. The method of experiment used by me, and which seems to have been followed by Prof. Haughton, I have found entirely unreliable, as will be hereafter shown.

3. I'utting $\beta=\left(\frac{2 \omega}{\pi}\right)^{2}$ in (3) and it may be reduced to the form-

$$
\frac{n}{t}=A-\beta n t
$$

Anyone who will take the trouble to calculate and co-ordinate the values $\frac{n}{t}$ and $n t$ from Prof. Haughton's observations, $\mathrm{pp}$. 468,474 , will see that these co-ordinated values form 2 curve, instead of a straight line. This is much more plainly marked in instead unplished series now in my possession. These latter expe. riments were made with an apparatus and method to be described in the next paper. They are more accurate than those before published, but not as accurate as can be obtained. It is certain, however, that the value of $w$ in (3) is not constant. Assuming it to be constant, however, and its value in the series referred to, to be constant, ho and 0.50. This illustrates very forcibly the futility of attempting theoretical reductions on the basis of assumed "laws," until we have first made sure of our facts.

Another series of mine which was also reduced by Prof. Haughton consisted in raising a varying weight, $w$, through the Haughton consisted in a time $t=1 \cdot 164$ sec. The experiments length of the conducted as before described. Mr. Haughton makes use of the above-quoted law in this reduction, and finds the relation to be-

$$
\left(v+\frac{a}{2}\right) n=\frac{A^{\prime}}{\left(w+\frac{a}{2}\right)}
$$

- For my right arm the constants are $A^{\prime}=1000$ and $a=20^{\circ}$. The comparison of $n$ (calc.) and $n$ (obs.) is satisfactory, and for want of space it is omitted. Solving (5) for $n$ and making $w=7 \cdot 0$, and making $t=1 \cdot 164$ in (3), and the values of $n$ are evidently identical, or -

$$
Z_{(70+1)^{2}} \frac{A^{\prime}}{1+\left(\frac{2 \omega}{\pi}\right)^{2}(\mathrm{r} \cdot 164)^{8}}
$$

where $Z$ should equal unity. Solving for $Z$ and introducing the values of the constants, and we find $Z=r_{4}$. Although this discrepancy was pointed out to him, Prof. Haughton has trans. ferred unreduced, from the observations leading to (5), the first value of $n(t=1 \cdot 164)$ in Table I. It is to be regretted that Prof. Haughton did not leave unpublished the last 43 pages of his in teresting and valuable work.

$$
\text { (To be continued.) }
$$

associated with lateral curvature, which lead him to the conclusion that cases of asymmetry of the two sides of the spinal column are due to original malformation of the bodies of the implicated vertebræ in the direction of a bi-lobed or double nucleus, and the subsequent unequal growth of the two halves. --Prof. Struthers has also a lengthy article on variations of the vertebrac and ribs in man, which will be read with interest in connection with that of Dr. Goodhart, and by all comparative anatomists, several very instructive abnormalities being described. -This paper is followed by one from the pen of Dean Byrne, on the development of the powers of thought in vertebrate animals in connection with the development of their brain; in which the author, by a comparison of the cerebral capacities of the different families of Mammalia with those of comparative anatomical structure and embryonic development, endeavours to prove that the functions of the anterior lobes of the brain belong to the act of thinking single objects of sense, those of the middle lobes to the act of thinking such objects with a sense of succession of them and as part of that succession, and those of the posterior lobes to the act of thinking a co-existence or succession of them as a case of a general principle.-Prof. M. Watson continues his contributions to the anatomy of the Indian elephant, describing the muscles and blood-vessels of the face and head. The same author also, with a drawing, describes a remarkable case of pharyngeal diverticulum, which opened on the free margin of the posterior pillar of the fauces, occupied the anterior triangle of the neck, and had a duct-like communication with its orifice, running between the internal and external carotids. - Dr. Arthur Ransome records the position of the heart's impulse in different postures of the body, from chest-rule measurements made by Mr. Wr. A. Patchett.-Baron A. de Watteville describes the cerebral and spinal nerves of Rana esculenta, from a series of dissections recently made.-Prof. Turner gives an account of the occurrence of Ploca greenlandica as a British species, from a specimen captured in Morecambe Bay and iden. tified by Mr. T. Gough.-Mr. J. C. Ewart records notes on the minute structure of the retina and vitreous humour. - Mr. I. C. Galton also has a note on the Epitrochleo-anconeus or Anconeus Sextus (Gruber) as a supplement to Prof. Gruber's paper, giving drawings of it in Tainanduce tctradactyla, Cholopus didac. tylhes, Phasiolomys zeombata, and Echidna sctosa. - The remaining short papers are by Mr. J. Reoch, on urinary pigments ; by Dr. J. J. Charter, on abnormalities of the arteries of the upper extremity ; by Mir. J. Harker, on a four-toed foetus without head or upper limbs; and by Dr. J. Cantlie and Mr. Bellamy, on the absence of the quadriceps-femoris muscle, and on the presence of a sixth lumbar vertebra, the first rib being rudimentary.

THe Scottis, Naturalist for January maintains the prestige of this interesting quarterly, now entered on its fifth year and third volume. It commences with an article of a more popular character than most :- "Illustrations of Animal Reason," by Dr. Lauder Lindsay, the authenticity of the anecdotes being vouched for by the writer. Among the hotanical notes, the most interesting is that of the discovery in Aberdeenshire by Mr. Sadler, during an excursion of the "Scottish Alpine Club," of two plants new to Britain, Carex frioidu and Salix Sadleri, the latter now described for the first time, and probably a hybrid between $S$. reticulata and $S$. lapponum or lanata. We have further insialments of "The Lepidoptera of Scotland," by Dr. Buchanan White, and "The Coleoptera of Scotland," by Dr. Sharp.

Pogrendorff's Annalen der Physile und Chemie, I874, No. Ir. - The frrst paper is by W. Muiller, of Perleberg, on the reduction of metallic oxides by hydrogen, and the application or this process for the quantitative determination of metals. The value of this method of quantitative determination depends on the fact that hydrogen reduces different metallic oxides at different temperatures. The results of Miuller's experiments show that the quantities of several metallic oxides may be determined in this way, when the mixtures are heated in hydrogen, and care is taken with regard to regulation of temperature. The method proved successful for copper and zinc, copper and silver, copper and bismuth, copper and cadmium, copper and lead, copper and tin, copper and iron; also for copper, iron, and zinc, and pretty well for copper, cadmium, and zinc; but it was unsuccessful in the case of silver and iron, silver and lead, arsenic and antimony. The apparatus is simple enough, but the experiments take a very long time, and will not be of much general practical use. - The next paper records some thermo-electric studies by E. Budde.-Dr, Kurd
Tile current number of the fournal of Anatomy and Physi. ology commences with a suggestive description, by Dr. J. F. Goodhart, of three cases of malformation of the spinal column * A few of these decimals inight be dropped without impairing the accuracy of the result. 